\title{
Bioavailability of oral hydrocortisone in patients with congenital adrenal hyperplasia due to 21-hydroxylase deficiency
}

\author{
E Charmandari, A Johnston ${ }^{1}$, C G D Brook and P C Hindmarsh
}

London Centre for Paediatric Endocrinology, University College London, London, UK

${ }^{1}$ Department of Clinical Pharmacology, St Bartholomew's and The Royal London School of Medicine and Dentistry, London, UK

(Requests for offprints should be addressed to P C Hindmarsh, Cobbold Laboratories, 7th Floor, Sir Jules Thorn Building, The Middlesex Hospital, Mortimer Street, London W1N 8AA, UK; Email: p.hindmarsh@ucl.ac.uk)

\begin{abstract}
The management of congenital adrenal hyperplasia due to 21-hydroxylase (CYP21) deficiency requires glucocorticoid substitution with oral hydrocortisone given twice or thrice daily. In paediatric practice little is known of the bioavailability of oral hydrocortisone tablets used in these patients. The aim of this study was to assess the bioavailability of oral hydrocortisone and to evaluate current replacement therapy in the light of cortisol pharmacokinetic properties.

We determined the bioavailability of hydrocortisone following oral and intravenous administration in sixteen (median age: $10 \cdot 9$ years, range: $6 \cdot 0-18 \cdot 4$ years) adequately controlled CYP21 deficient patients. Serum total cortisol concentrations were measured at 20-min intervals for $24 \mathrm{~h}$ while patients were on oral substitution therapy, and at 10-min intervals for $6 \mathrm{~h}$ following an intravenous bolus of hydrocortisone in a dose of $15 \mathrm{mg} / \mathrm{m}^{2}$ body surface area. The area under the serum total cortisol concentration versus time curve (AUC) following oral and intravenous administration of hydrocortisone was calculated using the trapezoid method. The bioavailability was estimated by dividing the corrected for dose AUC after oral hydrocortisone administration by the corrected for dose AUC after the intravenous hydrocortisone administration and was exemplified as a percentage. After oral administration of hydrocortisone in the morning, median serum total cortisol concentrations reached a peak of $729.5 \mathrm{nmol} / 1$ (range: $492-2520 \mathrm{nmol} / \mathrm{l}$ ) at $1.2 \mathrm{~h}$ (range: $0 \cdot 3-3 \cdot 3 \mathrm{~h}$ ) and declined monoexponentially thereafter to reach undetectable concentrations $7 \mathrm{~h}$ (range: 5-12 h) after
\end{abstract}

administration. Following administration of the evening hydrocortisone dose, median peak cortisol concentration of $499 \mathrm{nmol} / 1$ (range: $333-736 \mathrm{nmol} / \mathrm{l}$ ) was attained also at $1.2 \mathrm{~h}$ (range: $0 \cdot 3-3.0 \mathrm{~h}$ ) and subsequently declined gradually, reaching undetectable concentrations at $9 \mathrm{~h}(5-12 \mathrm{~h})$ after administration of the oral dose. After the intravenous hydrocortisone bolus a median peak serum total cortisol concentration of $1930 \mathrm{nmol} / 1$ (range: $1124-2700 \mathrm{nmol} / \mathrm{l}$ ) was observed at $10 \mathrm{~min}$ (range: $10-20 \mathrm{~min}$ ). Serum cortisol concentrations fell rapidly and reached undetectable levels $6 \mathrm{~h}$ after the hydrocortisone bolus. The absolute bioavailability of oral hydrocortisone in the morning was 94.2\% (90\% confidence interval (CI): 82.8-105.5\%) whereas the apparent bioavailability in the evening was estimated to be $128 \cdot 0 \%$ (90\% CI: $119 \cdot 0-138 \cdot 0 \%)$.

We conclude that the bioavailability of oral hydrocortisone is high and may result in supraphysiological cortisol concentrations within 1-2 $\mathrm{h}$ after administration of high doses. The even higher bioavailability in the evening, estimated using as reference the data derived from the intravenous administration of hydrocortisone bolus in the morning, is likely to reflect a decrease in the hydrocortisone clearance in the evening. Decisions on the schedule and frequency of administration in patients with congenital adrenal hyperplasia should be based on the knowledge of the bioavailability and other pharmacokinetic parameters of the hydrocortisone formulations currently available.

Journal of Endocrinology (2001) 169, 65-70

\section{Introduction}

Systemic corticosteroids are used as part of substitution therapy in the management of adrenocortical deficiency states, and physiological replacement is best achieved with a combination of hydrocortisone and the mineralocorticoid $9 \alpha$-fludrocortisone. In the management of congenital adrenal hyperplasia due to 21-hydroxylase (CYP21) deficiency, glucocorticoid substitution is with oral hydrocortisone given twice or thrice daily (British National Formulary 1998a).

Although hydrocortisone was designated as a drug whose different brands and dosage forms should be examined for bioequivalence (Fed Register 1976), very few studies have been performed to address its bioavailability. Most intravenous pharmacokinetic studies 
previously performed used hydrocortisone hemisuccinate as a water soluble pro-drug (Toothaker \& Welling 1982). However, after intravenous hemisuccinate administration of other corticosteroids, substantial amounts of the prodrug could be found in the urine making it a less than optimum standard for the assessment of bioavailability (Derendorf et al. 1985, Möllmann et al. 1988).

The aim of this study was to assess the bioavailability of oral hydrocortisone used in the treatment of patients with CYP21 deficiency and to evaluate current therapeutic practice in the light of cortisol pharmacokinetic properties.

\section{Materials and Methods}

\section{Patients}

Sixteen patients ( 4 males, 12 females; median age: $10 \cdot 9$ years, range: $6 \cdot 0-18 \cdot 4$ years) attending the London Centre for Paediatric Endocrinology were studied prospectively. Patients were consecutive attendees at the Outpatient Clinics and consisted of 9 prepubertal children, 5 pubertal and 2 postpubertal patients with classical CYP21 deficiency. All patients were adequately controlled and satisfactory suppression of the hypothalamo-pituitaryadrenal (HPA) axis had been confirmed by low adrenocorticotrophic hormone (ACTH) concentrations measured at $0800 \mathrm{~h}(<71 \mathrm{pg} / \mathrm{ml})$ and low serial measurements of 17-hydroxyprogesterone (17 OHP) $(<20 \mathrm{nmol} / \mathrm{l})$ concentrations. Patients were excluded from the study if there was evidence of central precocious puberty or other associated endocrine disorder.

All patients were on standard dose replacement therapy with oral hydrocortisone given twice $(n=8)$ or thrice $(n=8)$ daily (median dose: $17 \cdot 4 \mathrm{mg} / \mathrm{m}^{2}$ body surface area (SA)) and $9 \alpha$-fludrocortisone given once daily (median dose: $123 \mu \mathrm{g} / \mathrm{m}^{2}$ body SA). The median hydrocortisone morning dose was $10 \cdot 2 \mathrm{mg} / \mathrm{m}^{2}$ body SA (range: $4 \cdot 8$ $12.9 \mathrm{mg} / \mathrm{m}^{2}$ ) whereas the median hydrocortisone evening dose was $6 \cdot 1 \mathrm{mg} / \mathrm{m}^{2}$ body SA (range: $3 \cdot 4-9 \cdot 7 \mathrm{mg} / \mathrm{m}^{2}$ ). No patient had clinical or biochemical evidence of hepatic or renal disease and none was taking drugs known to alter cortisol pharmacokinetics.

The study was approved by the University College London Hospitals Committee on the Ethics of Human Research and informed written consent was obtained in all cases.

\section{Methods}

Patients were admitted to the Endocrine Unit one day prior to the investigations and complete physical examination, including pubertal staging and anthropometry, was performed by the same observer. Two indwelling venous catheters - one for the intravenous (i.v.) administration of hydrocortisone and the other for blood sampling - were inserted at least $12 \mathrm{~h}$ before sampling to allow a period of adaptation. Patients were allowed normal ambulatory activity and were not on restricted diet. Standard hospital meals were delivered at $0800 \mathrm{~h}, 1200 \mathrm{~h}$ and $1700 \mathrm{~h}$.

On the first day of the study patients were given their oral hydrocortisone (Hydrocortone, Merck Sharp \& Dohme Ltd) tablets at $0900 \mathrm{~h}$ and $2100 \mathrm{~h}$ or at $0800 \mathrm{~h}$, $1500 \mathrm{~h}$ and $2200 \mathrm{~h}$ depending on whether they were on a twice or thrice daily regimen. $9 \alpha$-Fludrocortisone was given with the morning or evening hydrocortisone tablets. Blood samples for serum total cortisol were collected at 20-min intervals and for a total of $24 \mathrm{~h}$ starting at $0800 \mathrm{~h}$.

On the second day of the study patients were given their usual dose of mineralocorticoid substitution at $0800 \mathrm{~h}$ and one hour later i.v. hydrocortisone sodium succinate (Solu-Cortef, Pharmacia \& Upjohn) was administered as a bolus in a dose of $15 \mathrm{mg} / \mathrm{m}^{2}$ body SA through the $1 \mathrm{st}$ cannula. Blood samples for serum total cortisol were collected through the 2nd cannula at 10-min intervals for a total of $6 \mathrm{~h}$ following the injection of hydrocortisone. Blood samples were spun, separated and stored at $-20{ }^{\circ} \mathrm{C}$ prior to assay.

\section{Cortisol assay}

Serum total cortisol was measured using the Coat-ACount radioimmunoassay (Coat-A-Count, DPC, Los Angeles, CA, USA). This is a solid phase radioimmunoassay with a sensitivity of $6 \mathrm{nmol} / 1$. The within-assay coefficients of variation were $5 \cdot 7 \%$ and $2 \cdot 6 \%$ at serum concentrations of $28 \mathrm{nmol} / 1$ and $552 \mathrm{nmol} / 1$ respectively. The between-assay coefficients of variation were $6.3 \%$ and $4 \cdot 5 \%$ at $138 \mathrm{nmol} / 1$ and $276 \mathrm{nmol} / 1$ respectively.

\section{Pharmacokinetics}

Bioavalability (F) of a drug is the fraction of the dose which reaches the systemic circulation as intact drug and is dependent upon drug absorption from the gastrointestinal tract into the portal circulation and first-pass hepatic clearance: $F=f_{g} \star f_{H}=f_{g} \star\left(1-E_{H}\right)$, where $f_{g}$ is the fraction absorbed, $\mathrm{f}_{\mathrm{H}}$ is the fraction that escapes removal by the liver at first-pass clearance and $\mathrm{E}_{\mathrm{H}}$ is the hepatic extraction ratio (Rowland \& Tozer 1980a, Birkett 1998b). Low hepatic extraction ratio drugs are poorly extracted by the liver, nearly all the dose gets through the liver first-pass and their bioavailability is essentially complete as long as they are well absorbed from the gut. On the contrary, high hepatic extraction ratio drugs are efficiently extracted by the liver on the first-pass through the liver and only a minor proportion of the administered dose reaches the systemic circulation intact. The bioavailabilty of these drugs is therefore low even when absorption is complete (Rowland \& Tozer 1980a).

Absolute bioavailability is the bioavailability measured against an intravenous reference dose, since the bioavailability of an intravenous dose is $100 \%$ by definition. 
Table 1 Pharmacokinetic parameters of oral and intravenous hydrocortisone

Oral

Median (range)

\section{Pharmacokinetic parameters Morning}

Baseline cortisol concentration $(\mathrm{nmol} / \mathrm{l})$ Peak cortisol concentration $(\mathrm{nmol} / \mathrm{l})$ Time peak concentration observed $\mathrm{AUC}\left(\mathrm{nmol} / \mathrm{I}^{*} \mathrm{~h}\right)$

$\mathrm{C}_{\max }(\mathrm{nmol} / \mathrm{l})$

$\mathrm{t}_{\max }(\min )$

Absolute bioavailability (\%)

\section{Evening}

Baseline cortisol concentration $(\mathrm{nmol} / \mathrm{l})$ Peak cortisol concentration ( $\mathrm{nmol} / \mathrm{l})$ Time peak concentration observed AUC (nmol/l*h)

$\mathrm{C}_{\max }(\mathrm{nmol} / \mathrm{l})$

$\mathrm{t}_{\max }(\min )$

Apparent bioavailability (\%)
Intravenous

Median (range)

\author{
Undetectable \\ 1930 (1124-2700) \\ $10(10-20)(\mathrm{min})$ \\ $209551 \cdot 5$ (158 821-337 737) \\ 2700 \\ 10
}

\author{
Undetectable \\ 499 (333-736) \\ $1 \cdot 2 \mathrm{~h}(0 \cdot 3-3 \cdot 0 \mathrm{~h})$ \\ 112775 (64 000-250 540) \\ 736 \\ 180 \\ 128.0 (90\% Cl: $119 \cdot 0-138 \cdot 0)$
}

Absolute bioavailability can be calculated following estimation of the area under the drug concentration versus time curve (AUC) following oral and i.v. administration of the same dose of the drug: $\mathrm{F}=\mathrm{AUC}_{\text {oral }} / \mathrm{AUC}_{\mathrm{iv}}$, where $\mathrm{AUC}_{\text {oral }}$ is the AUC following oral administration and $\mathrm{AUC}_{\mathrm{iv}}$ is the AUC following intravenous administration of the drug. Alternatively, when different oral and i.v. doses are used, bioavailability can be calculated following correction of the AUC for the dose given: $\mathrm{F}=$ $\mathrm{AUC}_{\text {oral }}{ }^{\star} \operatorname{Dose}_{\text {iv }} / \mathrm{AUC}_{\mathrm{iv}}{ }^{\star}$ Dose $_{\text {oral }} \Rightarrow \mathrm{F}=\mathrm{CL}_{\mathrm{iv}}{ }^{\star} \mathrm{AUC}_{\text {oral }} /$ Dose $_{\text {oral }} \Rightarrow \mathrm{F}=\mathrm{CL}_{\mathrm{iv}} / \mathrm{CL}_{\text {oral }}$, where $\mathrm{CL}_{\mathrm{iv}}=$ Dose $_{\mathrm{iv}} / \mathrm{AUC}_{\mathrm{iv}}$ is the true clearance of the drug estimated following intravenous administration of the drug, and $\mathrm{CL}_{\text {oral }}=$ Dose $_{\text {oral }} / \mathrm{AUC}_{\text {oral }}$ is the apparent clearance of the drug estimated after oral administration (Rowland \& Tozer 1980b, Birkett 1998a,b). The bioavailability of an oral formulation (test formulation), which is assessed against a second oral (reference) formulation, is referred to as relative bioavailability (Birkett 1998b).

The maximum plasma concentration $\left(\mathrm{C}_{\max }\right)$ is the experimental value with the highest plasma concentration of hydrocortisone. The time of the maximum plasma concentration $\left(t_{\max }\right)$ is the experimental data point when $\mathrm{C}_{\max }$ was measured.

\section{Pharmacokinetic and statistical analysis}

The area under the serum concentration versus time curve (AUC) was calculated using the trapezoid method. The area under the cortisol concentration versus time curve following oral administration of hydrocortisone $\left(\mathrm{AUC}_{\text {oral }}\right)$ was calculated from cortisol concentrations obtained at 20-min intervals following the morning and evening dose of oral hydrocortisone until cortisol concentrations were undetectable. The area under cortisol concentration versus time $(\mathrm{t})$ curve from point $\mathrm{t}=0 \mathrm{~min}$ to infinite time following intravenous administration of hydrocortisone $\left(\mathrm{AUC}_{\mathrm{iv}}\right)$ was calculated from cortisol concentrations measured at 10-min intervals after the i.v. hydrocortisone bolus for a total of $6 \mathrm{~h}$. Both $A U C_{\text {oral }}$ and $\mathrm{AUC}_{\mathrm{iv}}$ were corrected for the hydrocortisone doses given orally and intravenously respectively after all doses were standardised in molar terms $\left(1 \mathrm{mg}=10^{6} / 362 \cdot 46 \mathrm{nmol} / 1\right.$, where $362 \cdot 46$ is the molecular weight of cortisol). The absolute bioavailability in the morning was calculated by dividing the corrected for hydrocortisone dose $\mathrm{AUC}_{\text {oral }}$ following administration of the morning oral dose by the corrected for dose $\mathrm{AUC}_{\mathrm{iv}}$ and exemplified as a percentage. The apparent bioavailability of oral hydrocortisone in the evening was estimated by dividing the corrected for dose $\mathrm{AUC}_{\text {oral }}$ following administration of the evening dose by the corrected for dose $\mathrm{AUC}_{\mathrm{iv}}$ and exemplified as a percentage. The bioavailability was expressed as a 90\% confidence interval (CI) calculated using the two onesided test procedure (Schuirmann 1987, Nation \& Aansom 1994).

\section{Results}

All pharmacokinetic parameters estimated in our patients are summarised in Table 1. Baseline cortisol concentrations prior to oral or intravenous administration of hydrocortisone in the morning and in the evening were undetectable. After oral administration of the morning hydrocortisone dose, a maximum total cortisol concentration 


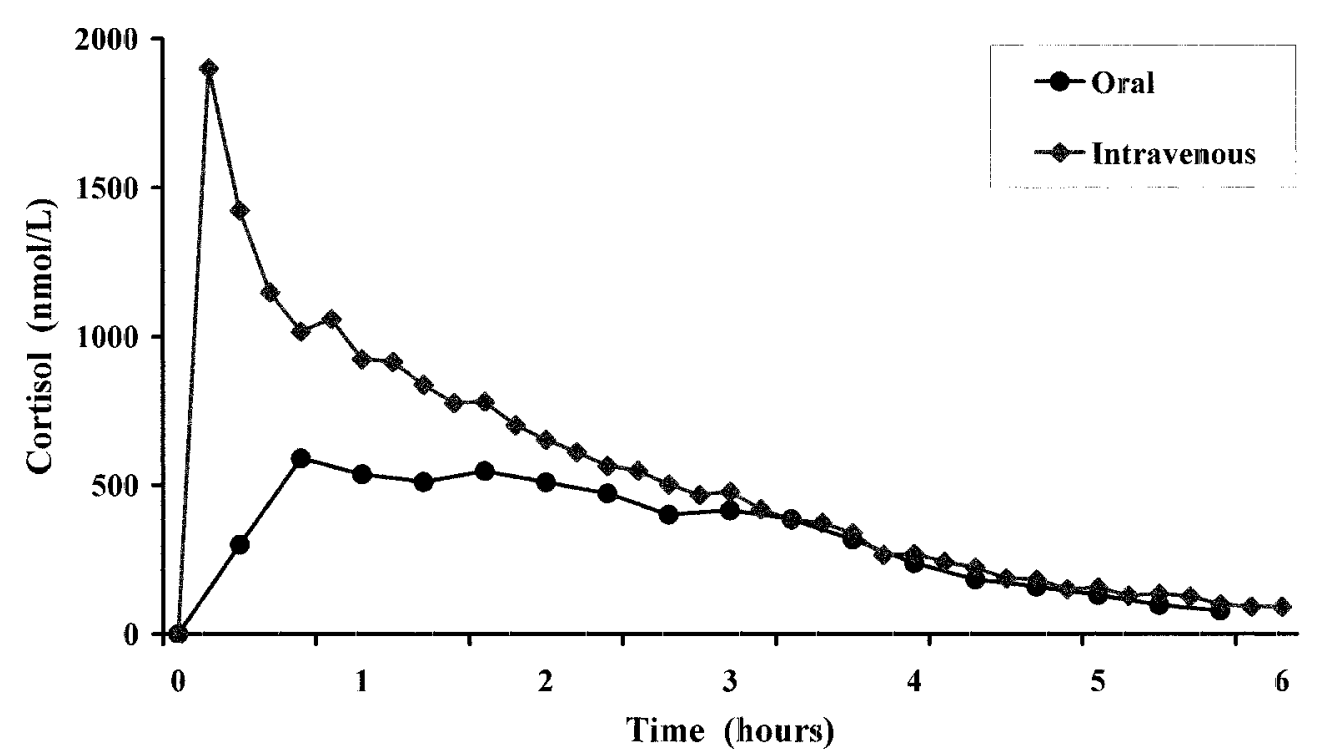

Figure 1 Median total cortisol concentrations following oral and intravenous administration of hydrocortisone in the morning. Cortisol concentrations decline monoexponentially and reach undetectable levels $6-7 \mathrm{~h}$ after administration.

$\left(\mathrm{C}_{\max }\right)$ of $2520 \mathrm{nmol} / 1$ was achieved at $\mathrm{t}_{\max }$ of $20 \mathrm{~min}$. Serum total cortisol concentrations reached a median peak of $729.5 \mathrm{nmol} / 1$ (range: $492-2520 \mathrm{nmol} / \mathrm{l}$ ) at $1.2 \mathrm{~h}$ (range: $0 \cdot 3-3 \cdot 3 \mathrm{~h}$ ) and declined monoexponentially thereafter to reach undetectable concentrations $7 \mathrm{~h}(5-12 \mathrm{~h})$ after administration of oral hydrocortisone (Fig. 1).

After oral administration of hydrocortisone in the evening, a $\mathrm{C}_{\max }$ of $736 \mathrm{nmol} / \mathrm{l}$ was observed at $\mathrm{t}_{\max }$ of $180 \mathrm{~min}$. Serum total cortisol concentrations reached a median peak of $499 \mathrm{nmol} / 1$ (range: $333-736 \mathrm{nmol} / \mathrm{l}$ ) also at $1.2 \mathrm{~h}$ (range: $0 \cdot 3-3 \cdot 0 \mathrm{~h}$ ) and subsequently declined gradually to reach undetectable concentrations $9 \mathrm{~h}$ (range: 5-12 h) after administration of oral hydrocortisone.

Following intravenous administration of hydrocortisone, a $\mathrm{C}_{\max }$ of $2700 \mathrm{nmol} / 1$ was achieved at $\mathrm{t}_{\max }$ of $10 \mathrm{~min}$. Median peak cortisol concentration was $1930 \mathrm{nmol} / 1$ (range: $1124-2700 \mathrm{nmol} / \mathrm{l}$ ) and was observed at $10 \mathrm{~min}$ (range: 10-20 min). Serum cortisol concentrations fell rapidly thereafter and reached undetectable levels $6 \mathrm{~h}$ after intravenous hydrocortisone administration. Cortisol concentrations before oral and i.v. administration of hydrocortisone were undetectable in all patients.

The absolute bioavailability of oral hydrocortisone in the morning $\left(\mathrm{F}_{\mathrm{m}}\right)$ was $94 \cdot 2 \%$ (90\% CI: 82.8-105.5\%) whereas the apparent bioavailabilty in the evening $\left(\mathrm{F}_{\mathrm{ev}}\right)$ was estimated to be $128 \cdot 0 \%$ (90\% CI: $119 \cdot 0-138 \cdot 0 \%)$. Since $\mathrm{F}_{\mathrm{m}}=\mathrm{CL}_{\mathrm{iv}} / \mathrm{CL}_{\text {oralm }}$ and $\mathrm{F}_{\mathrm{ev}}=\mathrm{CL}_{\text {iv }} / \mathrm{CL}_{\text {oralev }}$, it is evident that: $\mathrm{F}_{\mathrm{m}} / \mathrm{F}_{\text {ev }}=\mathrm{CL}_{\text {oralev }} / \mathrm{CL}_{\text {oralm }} \Rightarrow \mathrm{CL}_{\text {oralev }}=\mathrm{F}_{\mathrm{m}} \star \mathrm{CL}_{\text {oralm }} /$ $\mathrm{F}_{\mathrm{ev}} \Rightarrow \mathrm{CL}_{\text {oralev }}=0 \cdot 74^{\star} \mathrm{CL}_{\text {oralm }}$ and therefore the clearance of hydrocortisone in the evening is $26 \%$ lower than the hydrocortisone clearance in the morning.

\section{Discussion}

The pharmacokinetic parameters determined following intravenous administration of hydrocortisone sodium succinate (Solu-Cortef, Pharmacia \& Upjohn) in the present study are consistent with those previously reported after oral and intravenous administration of $20 \mathrm{mg}$ hydrocortisone (Hoechst) (Derendorf et al. 1991). The latter study was performed in healthy adult volunteers following suppression of the HPA axis by dexamethasone tablets given at $2200 \mathrm{~h}$ one day prior to the study. Our study was performed in much younger (median age: $10 \cdot 9$ years) patients with classical CYP21 deficiency who had minimal endogenous cortisol production, as evidenced by the undetectable cortisol concentrations before the oral and i.v. hydrocortisone doses were given. They were, therefore, reminiscent of patients with dexamethasone-induced HPA axis suppression in terms of endogenous cortisol production. The fact that the pharmacokinetic parameters of hydrocortisone derived from two different studies and using two different oral formulations are similar indicates that the two formulations used are bioequivalent, i.e. the extents and rates of absorption of the two formulations are so similar that there is likely to be no clinically important difference between their effects, either therapeutic or adverse.

Initial studies conducted to examine the bioavailability of hydrocortisone reported that approximately $50-60 \%$ of the drug was available to the systemic circulation following $10-20 \mathrm{mg}$ tablet or suspension doses of various hydrocortisone formulations, which were different to the 
formulation used in the present study (Toothaker \& Welling 1982, Patel et al. 1984). More recently, a similar study was performed in adults with primary or secondary adrenal insufficiency and used the same formulation of oral hydrocortisone as we did (Heazelwood et al. 1984). The bioavailability of oral cortisol (Hydrocortone, Merck Sharp \& Dohme Ltd) was calculated against an intravenous injection of hydrocortisone sodium succinate (Efcortelan, Glaxo) given as a bolus in a dose of $50 \mathrm{mg}$. In contradistinction to our findings, however, the authors reported a wide variation in cortisol bioavailability (range: 26-91\%, mean $54 \cdot 0 \pm 6 \cdot 9 \%$ ) secondary to considerable interindividual variation in the AUC of cortisol derived from intravenous and oral hydrocortisone administration. This variation in bioavailability was thought to be due to incomplete absorption secondary to intrinsic absorption effects, first-pass clearance at the liver, or both (Patel et al. 1984). Another possible factor that may account for this wide variation is that the intravenous dose of hydrocortisone used in the latter study $(50 \mathrm{mg})$ was much higher than the dose used in the study conducted by Derendorf et al. (1991) (20 mg) as well as in the present study $\left(15 \mathrm{mg} / \mathrm{m}^{2}\right)$.

Our observations are consistent with those of Derendorf et al. (1991) who estimated the absolute bioavailability of hydrocortisone to be $95.9 \%$ (s.D.: 19.6). The high oral bioavailability of hydrocortisone indicates that the drug is almost completely absorbed by the gastrointestinal tract and that the fraction of drug escaping first-pass hepatic clearance is high, thus implying a low hepatic extraction ratio. For low hepatic extraction ratio drugs, hepatic enzyme activity is not a major determinant of first-pass metabolism and oral bioavailability, although it plays an important role in hepatic clearance (Rowland \& Tozer 1980a). Therefore, factors such as gender, age or pubertal process that influence hepatic enzyme activity and in particular activity of $11 \beta$-hydroxysteroid dehydrogenase should have little or no effect on cortisol bioavailability (Weaver et al. 1998, Moore et al. 1999). In addition, the bioavailability of low hepatic extraction ratio drugs is not influenced significantly by the presence of liver disease, adverse effects are not observed and a modification of the dose is not usually required (British National Formulary 1998b).

The high oral bioavailability of hydrocortisone also indicates that, if absorption from the gastrointestinal tract is not impaired, an oral dose needs to be only $6 \%$ higher than an intravenous dose to achieve similar plasma concentrations and glucocorticoid effect. The oral route of administration of hydrocortisone is therefore almost as effective as the intravenous route and can be used safely in patients requiring systemic corticosteroid treatment (Birkett 1998c). Furthermore, such high bioavailability suggests that administration of frequent but modest doses of hydrocortisone may be a preferred option in the management of patients with congenital adrenal hyperplasia, since they will result in more physiological cortisol concentrations. Similarly, in the presence of an intercurrent illness, when doubling of the total daily hydrocortisone dose is recommended, it may be preferable to administer it in three or four divided doses rather than two divided doses.

The bioavailability of oral hydrocortisone in the evening was calculated using as reference the true clearance of hydrocortisone that had been estimated following the i.v. bolus of hydrocortisone in the morning. Since the bioavailability of a drug can never exceed $100 \%$, the increase in bioavailability in the evening is likely to reflect a decrease in the absolute clearance of hydrocortisone in the evening compared with the clearance in the morning. Given that the $\mathrm{F}_{\mathrm{m}} / \mathrm{F}_{\mathrm{ev}}=0.74$ it is inferred that the hydrocortisone clearance in the evening is $26 \%$ slower than the clearance in the morning. These findings may explain why cortisol concentrations following administration of the morning oral dose reached undetectable levels $2 \mathrm{~h}$ earlier (median: $7 \mathrm{~h}$, range: $5-12 \mathrm{~h}$ ) than cortisol concentrations attained after the evening oral dose (median: $9 \mathrm{~h}$, range: 5-12 h), despite the fact that the higher hydrocortisone doses were administered in the morning. However, the clearance of hydrocortisone in the evening can only be estimated reliably following intravenous administration of a hydrocortisone bolus and measurement of serum total cortisol concentrations at regular $(10 \mathrm{~min})$ intervals (Rowland \& Tozer 1980b, Birkett 1998a).

A decrease in cortisol clearance in the evening may be due to a circadian variation in corticosteroid binding globulin (CBG) concentrations and therefore alterations in the pharmacokinetic parameters of cortisol or a circadian variation in $\mathrm{CBG}$ binding capacity. Animal studies have demonstrated a circadian variation in CBG concentrations with a gradual increase throughout the day with peak concentrations attained at $1800 \mathrm{~h}$, and a subsequent decline during the night hours reaching nadir concentrations at 0600 h (Hsu \& Khun 1988, Meaney et al. 1992). Although similar studies are lacking in humans, a circadian variation of CBG binding capacity for prednisolone, with maximum binding observed at midnight and minimum binding observed at $0800 \mathrm{~h}$, has been reported in healthy subjects (Angeli et al. 1978). Alternatively, the decrease in cortisol clearance in the evening may relate to the circadian variation in ACTH secretion. Previous studies have demonstrated that elevated ACTH concentrations result in increased cortisol clearance by increasing its hepatic extraction (Zisper et al. 1976). Although these studies did not determine the plasma ACTH concentrations following the administration of the ACTH infusion, the physiological rise in $\mathrm{ACTH}$ concentrations early in the morning may be sufficient to result in increased cortisol clearance in the morning. These findings clearly have implications for replacement therapy hydrocortisone regimens, since it is likely that the evening oral hydrocortisone dose will provide glucocorticoid cover for a greater length of time than an equal dose administered in the morning. 
We conclude that the bioavailability of oral hydrocortisone is essentially complete and may result in supraphysiological cortisol concentrations within 1-2 h after administration of high doses. Decisions on the schedule and frequency of administration need to be made with caution and should be based on the knowledge of the pharmacokinetic parameters of hydrocortisone formulations currently used in the treatment of patients with congenital adrenal hyperplasia due to 21-hydroxylase deficiency. Further studies are required to examine the pharmacokinetic parameters of total cortisol in the evening after suppression of the HPA axis and to determine the pattern of CBG secretion and binding capacity for cortisol.

\section{Acknowledgements}

We thank Mrs Brankica Leonard for her technical support and Ms Jane Pringle, Ms Jane McLean and the staff on Carousel Ward, The Middlesex Hospital, London, for their support and contribution to the successful completion of this study. E C was supported by Children Nationwide Medical Research Fund.

\section{References}

Angeli A, Frajria R, De Paoli R, Fonzo D \& Caresa F 1978 Diurnal variation of prednisolone binding to serum corticosteroid-binding globulin in man. Clinical Pharmacology and Therapeutics 23 47-53.

Birkett DJ 1998a Clearance. In Pharmacokinetics, chapter 1, pp 1-8. Roseville, Australia: McGraw-Hill.

Birkett DJ 19986 Bioavailability and first-pass clearance. In Pharmacokinetics, chapter 5, pp 34-44. Roseville, Australia: McGraw-Hill.

Birkett DJ 1998c Designing dose regimens. In Pharmacokinetics, chapter 11, pp 96-108. Roseville, Australia: McGraw-Hill.

British National Formulary No 36 1998a Chapter 6, p 316. British Medical Association and The Royal Pharmaceutical Society of Great Britain.

British National Formulary No 3619986 Appendix 2, p 590. British Medical Association and The Royal Pharmaceutical Society of Great Britain.

Derendorf H, Rohdewald P, Möllmann H, Rehder J, Barth J \& Neveling D 1985 Pharmacokinetics of prednisolone after high doses of prednisolone hemisuccinate. Biopharmaceutics and Drug Disposition 6 423-432.

Derendorf H, Möllmann H, Barth J, Möllmann C, Tunn S \& Krieg M 1991 Pharmacokinetics and oral bioavailability of hydrocortisone. Journal of Clinical Pharmacology 31 473-476.
Fed Register 1976 Vol 42, p 1624.

Heazelwood VJ, Galligan JP, Cannell GR, Bochner F \& Mortimer RH 1984 Plasma cortisol delivery from oral cortisol and cortisone acetate: relative bioavailability. Journal of Clinical Pharmacology 17 $55-59$.

Hsu BR \& Khun RW 1988 The role of adrenal in generating the diurnal variation in circulating levels of corticosteroid-binding globulin in the rat. Endocrinology 122 421-426.

Meaney MJ, Aitken DH, Sharma S \& Viau V 1992 Basal ACTH, corticosterone and corticosterone-binding globulin levels over the diurnal cycle, and age-related changes in hippocampal type I and type II corticosteroid receptor binding capacity in young and aged, handled and non-handled rats. Neuroendocrinology 55 204-213.

Möllmann H, Rohdewald P, Barth J, Möllmann C, Verho M \& Derendorf H 1988 Comparative pharmacokinetics of methylprednisolone phosphate and hemisuccinate in high doses. Pharmaceutical Research 8 509-513.

Moore JS, Monson JP, Kaltsas G, Putigano P, Wood PJ, Sheppard MC, Besser GM, Taylor NF \& Stewart PM 1999 Modulation of $11 \beta$-hydroxysteroid dehydrogenase isozymes by growth hormone and insulin-like growth factor: in vivo and in vitro studies. Journal of Clinical Endocrinology and Metabolism 84 4172-4177.

Nation RL \& Aansom LN 1994 Bioequivalence requirements for generic products. Pharmacology and Therapeutics 62 41-55.

Patel RB, Rogge MC, Sellen A, Goehl TJ, Shah VP, Prasad VK \& Welling PG 1984 Bioavailability of hydrocortisone from commercial 20-mg tablets. Journal of Pharmacentical Science 7 964-966.

Rowland M \& Tozer TN 1980a Hepatic clearance and elimination. In Clinical Pharmacokinetics: Concepts and Applications, chapter 6, pp 65-66. Philadelphia: Henry Kimpton Publishers.

Rowland M \& Tozer TN $1980 b$ Intravenous dose. In Clinical Pharmacokinetics: Concepts and Applications, chapter 7, pp 79-96. Philadelphia: Henry Kimpton Publishers.

Schuirmann DJ 1987 A comparison of the two one-sided tests procedure and the power approach for assessing the equivalence of average bioavailability. Journal of Pharmacokinetics and Biopharmaceutics 15 657-680.

Toothaker RD \& Welling PG 1982 Effect of dose size on the pharmacokinetics of intravenous hydrocortisone during endogenous hydrocortisone suppression. Journal of Pharmacokinetics and Biopharmaceutics 10 147-156.

Weaver JU, Taylor NF, Monson JP, Wood PJ \& Kelly WF 1998 Sexual dimorphism in 11ß-hydroxysteroid dehydrogenase activity and its relation to fat distribution and insulin sensitivity: a study in hypopituitary subjects. Clinical Endocrinology 49 13-20.

Zisper RD, Speckart PF, Zia PK, Edmiston WA, Lau FYK \& Horton R 1976 The effect of ACTH and cortisol on aldosterone and cortisol clearance and distribution in plasma and whole blood. Journal of Clinical Endocrinology and Metabolism 43 1101-1109.

Received in final form 7 November 2000

Accepted 8 December 2000 